\title{
ELBA VARGAS BECERRA
}

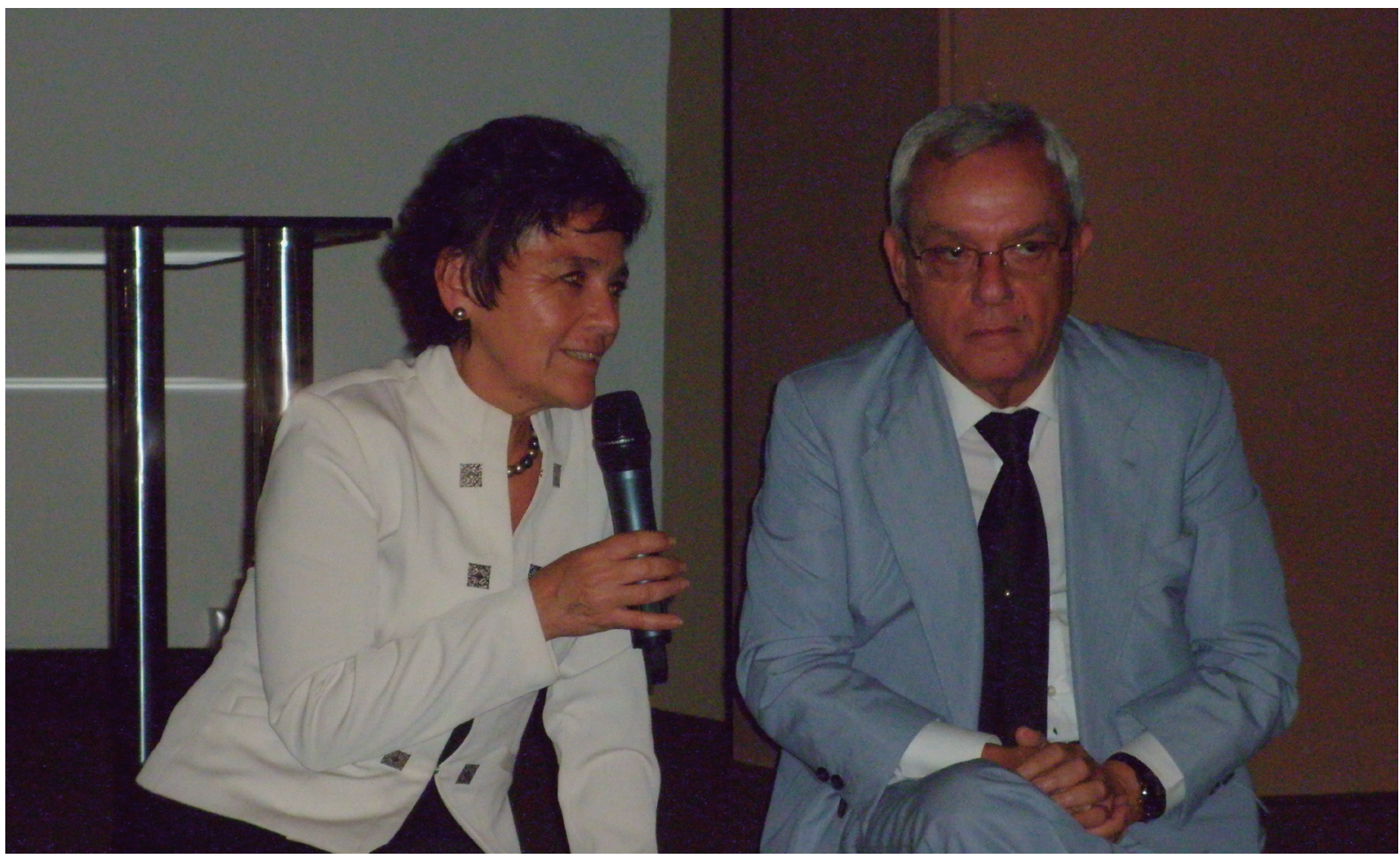

Arquitecta Elba Vargas Becerra presentando la conferencia del Dr. Eusebio Leal, director de la Oficina del Historiador de La Habana Fuente: Archivo fotográfico personal Caleb Sagua, 2012.

Elba Vargas, desde su juventud -"juventus" y buen ánimo que la caracterizaron durante su lamentablemente corta vida, pues todavía tenía mucho que dar- contó con la orientación de su padre, el destacado arquitecto Oscar Vargas Méndez, a quien también siguió su hijo del mismo nombre.

Siendo estudiante en la Facultad de Arquitectura, Urbanismo y Artes de la Universidad Nacional de Ingeniería, ya colaboraba con su hermano y padre en importantes proyectos urbanos y arquitectónicos, había ganado varios concursos y una segunda mención honrosa en el Concurso "Lima sí puede cambiar" (1991).

En los años 70 se creó el Instituto Nacional de Cultura, durante la 'época de oro', como la llaman algunos (me abstengo). Un punto notable aconteció con la organización, por quien escribe y el Arq. Frederick Cooper, del Centro de Investigación y Restauración de Bienes Monumentales (CIRBM-INC), con local nuevo -la casa Canevaro en el Jr. Áncash-, buen presupuesto y una visión integral del patrimonio. Para ello, se contó con la experiencia del recordado Arq. Alejandro Alva Manfredi -Jefe del Departamento de Monumentos Histórico Artísticos-, el destacado arqueólogo Luis G. Lumbreras (Departamento de Arqueología), el Dr. Rogger Ravines (Departamento de Investigación) y el Lic. Teófilo Salazar (Departamento de Restauración de Bienes Muebles), además del gran fotógrafo Wilfredo Loayza, encargado del Laboratorio de Imágenes, quien convenció a su maestro don Abraham Guillén de vender al CIRBM sus miles de negativos por S/.500,000.00 (de la época), a pesar de que le ofrecían el doble en EE. UU., negativos de los que creo quedan la mitad a causa de 'descuidos'y mudanzas posteriores.

Se convocó a jóvenes para cubrir las numerosas plazas y de allí surgieron brillantes profesionales: Elba; Juanita Remolina; Juan Luis Birimiza (los tres lamentablemente fallecidos); Bertha Estela; José María Gálvez; Jorge Ma- 
devenir Vol. 3, Nº6, JULIO-DICIEMBRE 2016, PP. 5-6 - IN MEMORIAM I ISSN 2312-7570

UNIVERSIDAD NACIONAL DE INGENIERÍ, LIMA

rroquín (gran estructuralista); Jorge Cosmópolis, radicado en Chiclayo; y Julio Chang Lam, radicado en Trujillo. Titulado en Alemania llegó el Arq. Ramiro Salas, quien dirigió CIRBM varios años.

Elba destacó siempre por su entusiasmo y don de gentes, y junto con muchos de los antes mencionados fue pronto a especializarse en los Cursos de Restauración INC / UNESCO Perú 39 que organizamos en el Cusco a partir de 1975 junto con el recordado maestro arquitecto José De Mesa y el Arq. Roberto Samanez, especialista peruano con gran experiencia por su formación en Roma.

Ella los aprovechó al máximo, al igual que a otros grandes maestros, como el recientemente fallecido Leonardo Benévolo (Italia), Teresa Gisbert (Bolivia), Carlos Flores Marini (México), Graziano Gasparini (Venezuela), y los peruanos Víctor Pimentel Gurmendi, José García Bryce, Santiago Agurto y Carlos Williams, estos dos últimos ya fallecidos.

A su regreso del Cusco Elba se convirtió en eficaz colaboradora del ya mencionado Arq. Alva Manfredi y secretaria de la Comisión Nacional Calificadora de esta área, la cual yo presidía e integraban los arquitectos García Bryce, Williams, Cooper y Salas, además de la Dra. María Rostworoski -como asesora histórica-. Teníamos un arma potente en la Resolución Suprema № 2900-72-ED, que la Dra. Martha Hildebrandt hizo firmar al Gral. Juan Velasco, en la cual se declara oficialmente como monumentos a más de 500 edificios, ambientes urbanos y centros históricos de todo el Perú; esta salvó de la demolición a muchos valiosos edificios, como la casa del Mariscal Castilla, declarada finca ruinosa y apta para ser demolida por la Municipalidad de Lima. La gestión que realizó Elba en este caso fue fundamental.

En 1988 pasó a la Sociedad de Beneficencia Pública de Lima como gerente ejecutiva del Plan de Destugurización y Revaloración de su patrimonio inmobiliario, donde realizó una valiosa gestión que la llevó hasta ser directora general de Recursos y Proyectos entre 1991 y 1992.

Quizá donde más pudo lucir su experiencia y cualidades fue en su larga vinculación al Patronato de Lima. Esta institución, que tanto ha contribuído a la conservación de Lima y su patrimonio cultural, fue fundada en 1989 por iniciativa del destacado empresario Eduardo Arrarte, bien asesorado por el gran estudioso y limeñista Juan Gunther Doering (ver "In memoriam", Devenir 1). En dicha plataforma, Elba siempre fue un valioso y entusiasta apoyo para Gunther en toda la notable labor que realizó el Patronato, hasta que lamentablemente desapareció años después por la desidia de los directivos que sucedieron a Arrarte.

Elba, como directora del Centro de Investigación y Estudios de Lima del Patronato, fue la eficiente organizadora de varios foros, así como de los seminarios semestrales de Historia y Restauración, orientados a promover el conocimiento y valoración entre los estudiantes de arquitectura.

El Patronato logró, hace 25 años, la inscripción de buena parte del centro histórico de Lima en la Lista del Patrimonio Mundial, gracias al empeño de Arrarte y Gunther, quienes viajaron varias veces a París. El Municipio de Lima en nada ayudó y el alcalde metropolitano de Lima de aquel entonces no quiso viajar para coordinar con la UNESCO e ir convenciendo al Comité del Patrimonio Mundial.

El último escollo fue el reclamo de Unesco de un reglamento actualizado e integral para el centro histórico, en el que muchos colaboramos, donde la coordinación de Elba fue fundamental. El equipo de profesionales y técnicos que elaboró el reglamento fue liderado por el Arq. Santiago Agurto Calvo (director del proyecto). Este contaba con 16 profesionales: Elba fue uno de los más destacados.

Siempre preocupada por la ciudad, fue asesora y luego gerente de PROLIMA (2012-2013) durante la gestión de la alcaldesa metropolitana de Lima Sra. Susana Villarán.

Nunca se olvidó de su alma mater. Estuvimos juntos en varios cursos y talleres, y cuando la UNI en 1993 tomó la acertada decisión de abrir la maestría en Restauración de Monumentos en Arquitectura y Urbanismo -luego evolucionada en Conservación del Patrimonio Edificado-, fue designada su coordinadora académica, puesto en el que realizó una gran labor durante muchos años.

Elba, fallecida el 26 de agosto de 2016, siempre será recordada en Lima por todo lo que hizo en favor de nuestra histórica pero aún maltratada ciudad.

\section{José Correa Orbegoso}

